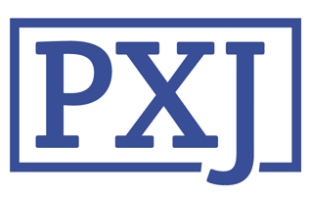

Patient Experience Journal

Volume 3 | Issue 2

Article 15

2016

\title{
Patient Advisors: How to implement a process for involvement at all levels of governance in a healthcare organization
}

\author{
Marie-Pascale Pomey \\ University of Montreal \\ Edith Morin \\ Catherine Neault \\ Veronique Biron \\ Lise Houle
}

See next page for additional authors

Follow this and additional works at: https://pxjournal.org/journal

Part of the Health and Medical Administration Commons, Health Policy Commons, and the Health Services Research Commons

\section{Recommended Citation}

Pomey M, Morin E, Neault C, Biron V, Houle L, Lavigueur L, Bouvette G, St-Pierre N, Beaumont M. Patient Advisors: How to implement a process for involvement at all levels of governance in a healthcare organization. Patient Experience Journal. 2016; 3(2):99-112. doi: 10.35680/2372-0247.1134.

This Article is brought to you for free and open access by Patient Experience Journal. It has been accepted for inclusion in Patient Experience Journal by an authorized editor of Patient Experience Journal. 


\section{Patient Advisors: How to implement a process for involvement at all levels of governance in a healthcare organization}

\section{Cover Page Footnote}

Acknowledgement The authors wish to acknowledge the unique contributions to this study made by the entire team of the CSSS-E and by the patients and patient advisors. They thank the Canadian Foundation for Healthcare Improvement for their financial support as well as their continued assistance throughout this project. Finally, the co-authors wish to thank Patrick Riley for translating the article into English.

\section{Authors}

Marie-Pascale Pomey, Edith Morin, Catherine Neault, Veronique Biron, Lise Houle, Louise Lavigueur, Guy Bouvette, Nicole St-Pierre, and Martin Beaumont 


\title{
Patient Advisors: How to implement a process for involvement at all levels of governance in a healthcare organization
}

Marie-Pascale Pomey, University of Montreal, marie-pascale.pomey@umontreal.ca

Edith Morin, Centre de santé et de services sociaux de Mauricie-Centre-du-Québec, edith_morin@hotmail.com

Catherine Neault, Centre de santé et de services sociaux de Mauricie-Centre-du-Québec,

Catherine_neault_energie@ssss.gouv.qc.ca

Veronique Biron, Centre de santé et de services sociaux de Mauricie-Centre-du-Québec,

Veronique_Biron_Energie@ssss.gouv.qc.ca

Lise Houle, Centre de santé et de services sociaux de Mauricie-Centre-du-Québec, houle110@cgocable.ca

Louise Lavigueur, Centre de santé et de services sociaux de Mauricie-Centre-du-Québec, louise_lavigueur@ssss.gouv.qc.ca

Guy Bouvette, Centre de santé et de services sociaux de Mauricie-Centre-du-Québec, gb861@botmail.com

Nicole St-Pierre, Centre de santé et de services sociaux de Mauricie-Centre-du-Québec, Nicole_St-

Pierre_energie@ssss.gouv.qc.ca

Martin Beaumont, Centre de santé et de services sociaux de Mauricie-Centre-du-Québec, Martin_beaumont@ssss.gouv.qc.ca

\begin{abstract}
Patient involvement at the operational (clinical care and services), tactical (management), and strategic (board of directors and executive management) levels of establishments is increasingly sought after. To address this specific challenge, a Canadian healthcare organization, the Centre intégré universitaire de santé et de services sociaux de la Mauricie-et-du-Centre-du-Québec, has developed an integrated strategy based on three principles: (1) shared leadership between a patient and a manager to build the strategy; (2) a clear process for recruiting, training, and coaching patient advisors (PA) so that they can participate in decision-making at the various levels of governance of the establishment; and (3) a feedback process for improving the strategy over time. This initiative gave rise to a pool of 30 patient advisors who reviewed documentation (39.07\%), presented testimonies to establishment practitioners (13.73\%), participated in process improvement activities $(12.97 \%)$ and committees $(8.93 \%)$, and helped train students in health sciences $(11.61 \%)$. It also led to the development of a request form for all persons wishing to involve PAs in their projects. This PA involvement, highly appreciated by both managers (94\%) and PAs (81\%), brought back the fundamental meaning of the patient-practitioner relationship and helped incorporate patients' experiential knowledge into the care and service improvement process. This strategy can serve as a model for other organizations wishing to structure optimal patient engagement at the different levels of governance of their organization.
\end{abstract}

\section{Keywords}

Patient partnership; patient-centred care; hospitals; healthcare organizations; patient advisor; patient-as-partner

\section{Note}

The authors wish to acknowledge the unique contributions to this study made by the entire team of the CSSS-E and by the patients and patient advisors. They thank the Canadian Foundation for Healthcare Improvement for their financial support as well as their continued assistance throughout this project. Finally, the co-authors wish to thank Patrick Riley for translating the article into English and Nathalie Clavel to revise the references.

In recent years, the role of patients in the healthcare system has become a vital one, whether one considers patients' direct involvement in their own care and services, reflecting greater competency and health knowledge regarding their illness, or their experiential knowledge of decision-making. ${ }^{1-6}$ Their involvement can also focus on the continuous improvement of the care and services they receive. Indeed, as patients have an overall view of the care process, they are well positioned to share their knowledge to identify quality or safety issues and suggest solutions. ${ }^{7-9}$ Their involvement can take various forms, such as participating in continuous quality improvement committees,${ }^{10}$ contributing to Lean Six-Sigma processes, ${ }^{11}$ developing best practice guides, ${ }^{12}$ or writing documentation for patients. ${ }^{13}$ They can also be involved in healthcare organization (HCO) governance through user

Patient Experience Journal, Volume 3, Issue 2 - Fall 2016

C The Author(s), 2016. Published in association with The Beryl Institute and Patient Experience Institute

Downloaded from www.pxjournal.org 
committees or boards of directors. ${ }^{14,15}$ Finally, they can also be included at a more political level of healthcare system governance..$^{1,16-18}$

However, studies conducted on patient involvement in establishments have revealed limitations to the real added value of this involvement. ${ }^{19}$ Often, patients are illequipped to interact in a professional world that has its own set of rules, and professionals have trouble understanding why patients' views should be brought to bear on their practices. ${ }^{7,20,21}$ Nevertheless, it is currently inconceivable for a healthcare organization not to take into account the views of the patients under their care or capitalize on patients' knowledge to improve care and service delivery. In this context, the Centre de santé et de services sociaux de l'Énergie (CSSS-E) ${ }^{19}$ decided in 2014 to implement a structured process for patient partnership across the entire establishment. Indeed, the CSSS-E developed an integrated strategy for recruiting and training patient advisors so that they can participate in decisionmaking at the various levels of governance of the establishment, namely the operational (clinical care and services), tactical (management), and strategic (board of directors and executive management) levels. The intervention received funding from the Canadian Foundation for Healthcare Improvement (CFHI) over an 18-month period. ${ }^{22}$ However, at the end of the implementation, the CSSS-E was merged with other establishments to form the Centre intégré universitaire de santé et de services sociaux de la Mauricie-et-du-Centredu-Québec (CIUSSS-MCQ). ${ }^{10}$

The objective of this article is to: 1 ) describe the implementation strategy over its 18 months; 2) analyze the activities developed, how the practitioners and patients involved viewed them, and the factors that facilitated or hindered implementation; 3) discuss the challenges generated by the merger and 4) provide recommendations for establishments interested in setting up a framework for patient involvement.

\section{Developing a structured process for patient involvement}

As part of its strategic planning for 2012-2015, the CSSS-E decided to implement an approach for partnership of care and services with patients. In the partnership model, patients are viewed as co-producers of their care. The approach is founded on acknowledging patients' experiential knowledge, considering patients as full-fledged team members, and recognizing the need to make decisions based on patients' life plans. ${ }^{3,24}$ Thus, from the partnership perspective, decision-making and quality care actions are based on a combination of health professionals' scientific knowledge and patients' experiential knowledge, gained from living with the disease. $^{25}$
At the CSSS-E, the department for teaching, research, and professional practices was given the mandate to develop a structured process for recruiting patients to participate in working groups at the clinical, organizational, and strategic levels, to improve the quality of care and services in the establishment. This mandate was assigned by executive management, which had included development of partnership of care and services in its 2012-2015 strategic plan for the establishment. Executive management also made the necessary funding available to hire staff and obtain methodological support for patient participation from the University of Montreal, which had developed an expertise in patient engagement. Thus, a joint clinicaladministrative/patient team was formed, consisting of a social work counselor, a senior nursing care advisor, and a patient counselor who was involved two days a week. The patient counselor had already participated in continuous quality improvement committees and was interested in helping to fulfill the team's mandate on a part-time basis. Moreover, a collaboration contract was signed with the Collaboration and Patient Partnership Unit (CPPU) of the faculty of medicine of the University of Montreal for support in integrating patients into the different levels of governance of an HCO. In addition, with the CFHI grant, a collaboration was initiated with a researcher from the University of Montreal to assess the strategy put in place.

To begin, the team developed a reference framework for deploying partnership of care and services, which included the notion of interprofessional collaboration. The purpose of the framework was to translate the organization's vision as to how these two critically linked approaches should be integrated. It also aimed to identify prerequisites, challenges, and winning conditions for the deployment and sustainability of a real culture of partnership and collaboration. The framework also highlights the unique role assigned to users in various instances of decisionmaking at the operational, tactical, and strategic levels. Based on the framework, a manual for patient involvement was developed, which described the engagement process using diagrams and concrete examples (see Figure 1).

Although designed for clinical settings, partnership of care and services was also applied at the organizational level, in the form of patient advisors (PA), i.e. patients who, having been through a significant care episode, have gained experiential knowledge regarding their illness and the healthcare system. ${ }^{26}$ Once the process was established, the coordinating team met with the 12 establishment's departments, to make them aware of the benefits of involving PAs at all three levels of governance, and asked wards to identify motivated patients willing to put their knowledge to use by joining working groups, ${ }^{27}$ drafting documents for patients, or supporting other patients. ${ }^{28}$

As part of the process, PA candidates are interviewed by the social work counselor and the patient counselor to 
Figure 1. Patient advisor involvement process

\section{Patient advisor involvement process}

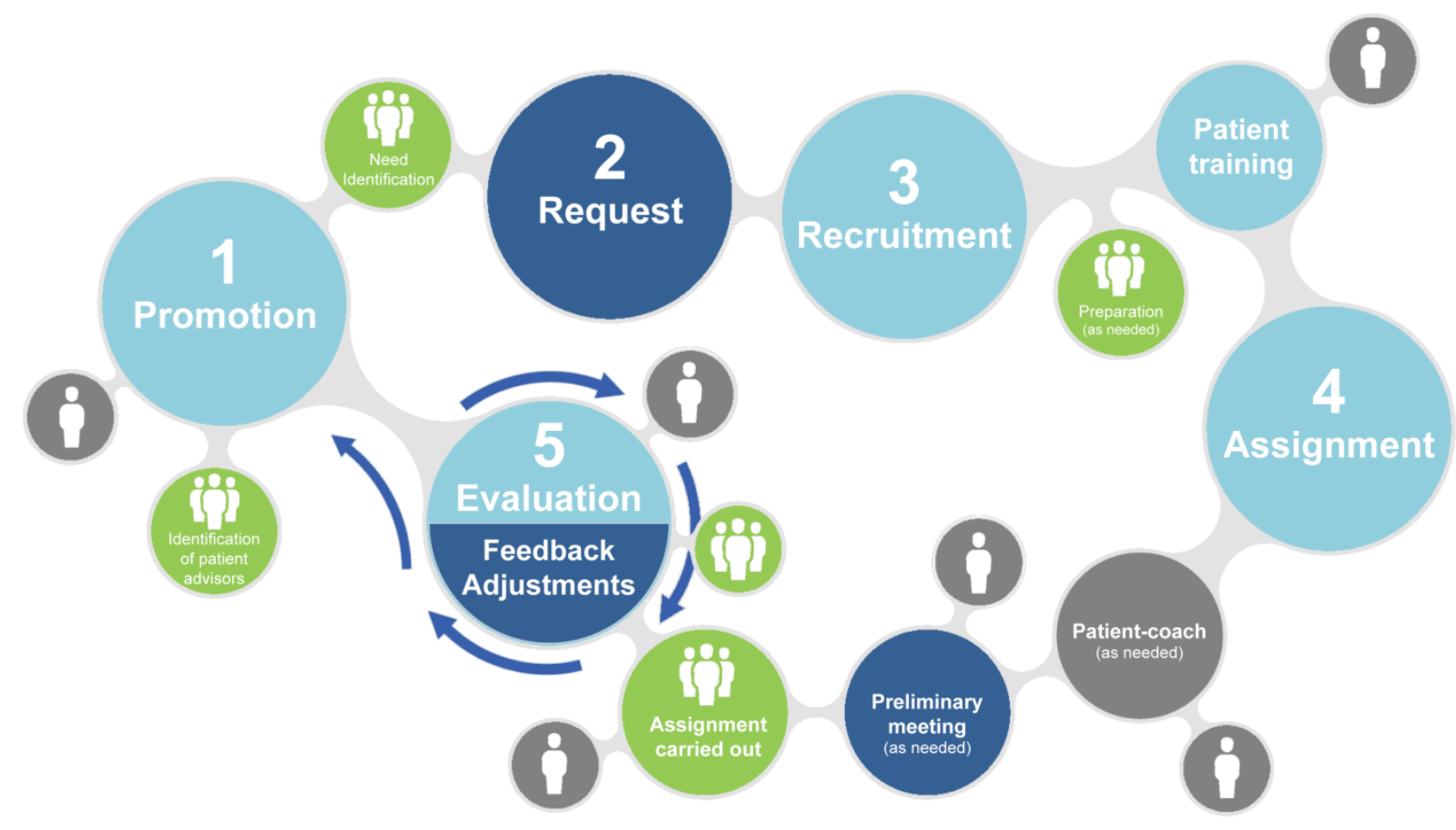

LEGEND

ensure that certain criteria are met, ${ }^{25,29}$ namely that they 1 ) are capable of critical judgment and display a generally constructive attitude during their interventions with the healthcare system, 2) are able to distance themselves from their own experience of living with illness and to learn to live with it, and 3) can generalize their experience to other care contexts. Candidates who are selected are asked to indicate their desired degree of involvement and their availability. This allows for personalized management of the PA pool. Over time, PAs' level of involvement may vary depending on their health status, their availability, and the competencies they develop. All PAs undergo an initial half-day training session provided by the coordinating team, covering the theoretical basis of patient partnership of care and services, the establishment's organization, and the different potential roles for PAs. In this way, the establishment builds a pool of patients who can participate in partnership activities according to the establishment's needs. Concurrently, health professionals who are likely to be working with PAs receive a half-day training on the concept of partnership of care and services, also delivered by the coordinating team.
Once PAs have been involved in different activities and have more experience in partnership, the coordinating team can invite them to coach newly recruited PAs. Those more experienced patients, referred to as patient-coaches, were brought onboard to help new PAs during the initial preparation and integration stage, and then throughout their assignments to ensure patients are comfortable in their assigned activities and are able to discuss any challenges they encounter. This coaching enabled less experienced PAs to work on more complex assignments from the start.

Teams requesting PAs have to fill out a request form to identify specific assignment-related needs (Appendix 1). This request form, intended as a tool for communication between partnership coordinators, teams, PAs, and managers, also serves to collect data. It includes: 1) the level of the request (care and services, tactical, or strategic); 2) the nature of the request (input on documentation, patient testimony, project implementation, process improvement activities, joint training, or committee participation), and 3) the purpose of the request (quality and safety of care and services, accessibility of care and 
services, or optimization of resources). Once a request is sent to the coordinating team, the latter is responsible for identifying, in consultation with the parties involved, PAs who could potentially participate in the designated activity.

Thus, PAs may participate in activities at different levels of the establishment. At the operational/clinical level, PAs can help by supporting planned interventions for complex situations, reviewing information pamphlets, or providing testimony. For example, PAs were involved in writing two pamphlets, one addressed to patients and the other to health professionals, presenting: 1) the principles of partnership of care and services, 2) the benefits of patient advisor involvement, and 3) the process to follow for involving a PA. At the tactical level, PAs helped develop action plans, sat on continuous improvement committees (CIC), and contributed to Kaizen activities. And finally, on the strategic level involving directors, PAs were called on to review strategic planning, provide input on spatial reorganization of services, and participate in strategic Kaizen activities.

At the end of each assignment, the partnership coordinators conduct an evaluation of the satisfaction of the PAs and the team and share the results with all participants.

\section{Evaluation strategy}

Qualitative and quantitative data were collected over the 18 months of implementation. First, all team requests for PAs were compiled and analyzed to track the number of PAs trained, the number of requests fulfilled, the distribution of requests by governance level and by department and the distribution of requests by objective and overall purpose. Later, at the end of the evaluation period, questionnaires were sent to managers and practitioners who had worked with PAs, as well as to the PAs themselves, to find out their perceptions regarding: 1) the degree of relevance of PA involvement in the project, 2) the level of involvement of PA during project activities, and 3) whether the PAs were well prepared to participate in the project. Finally, seven (T1) and 18 (T2) months into the implementation, interviews were conducted with the executive director and various directors, and group discussions were held, to ask the same questions as in the questionnaire, as well as to identify organizational factors that had helped or hindered implementation of the strategy. At T1, eight interviews were held, with the executive director; the assistant executive director; the director of teaching and research; the director for public health/quality of partner and community relations; the director of professional practices; the head of the general medicine department/president of the user committee; the senior advisor for multidisciplinary services and lead for patient partnership; and the expert patient recruited to deploy the initiative. Three discussion groups were held, the first with clinical managers $(n=10)$, the second with physicians $(n=3)$, and the last with PAs $(n=8)$. At T2, an interview was held with the senior advisor and expert patient co-leading the project. All interviews and group discussions were recorded and transcribed. The transcripts were then analyzed by two people, who classified emergent themes according to the project's objectives. All participants signed a consent form.

\section{Patient involvement at various levels of governance}

Between 2013 and 2014, 114 requests were fulfilled, originating from 10 out of 12 total departments (83\%). For each one, PAs were selected, trained, and coached to work in collaboration with the teams. In total, 29 PAs participated in these activities. As the involvement of more than one patient per request was encouraged, a total of 200 patient assignments (patient-presences) were completed. Patient involvement was mainly at the level of care and services $(69.81 \%)$, but also at the tactical $(21.94 \%)$ and strategic $(8.25 \%)$ levels.

Of the 114 requests, $39.07 \%$ were for input on documentation, $13.73 \%$ for presentation of patient testimonies, $13.69 \%$ for project implementation, $12.97 \%$ for process improvement activities, $11.61 \%$ for joint training (manager/practitioner/patient), and $8.93 \%$ for participation on committees (see Table 1).

More specifically, concerning input on documentation, patients were asked to give their opinion on educational tools provided to patients, on the establishment's revised code of ethics, and on tools for evaluation of partnership. Patients provided testimony at the annual meeting of all the establishment's managers and at welcoming events for new employees, among other occasions, where they illustrated the establishment's values (respect, solidarity, consistency, empathy, and excellence) by describing their own experience of care and services. For process improvement activities, PAs were included in continuous improvement of quality committees (Table 2) or Kaizen, to improve processes. For training, as the establishment hosts residents/interns in various health professions (physicians, nurses, social workers, psychologists, pharmacists, etc.), training is offered in an interdisciplinary format and is led by a patient/healthcare professional duo. For example, to reduce the number of complaints, the complaints commissioner and a patient present cases to the trainees and help them understand how it might have been avoided through patient partnership. Finally, an example of project implementation was the opening of the library to all patients, which involved purchasing documents for therapeutic education, providing reading material for hospitalized patients, and identifying patients' top picks, books that helped them during their care and service experience. 
Table 1. Request objectives

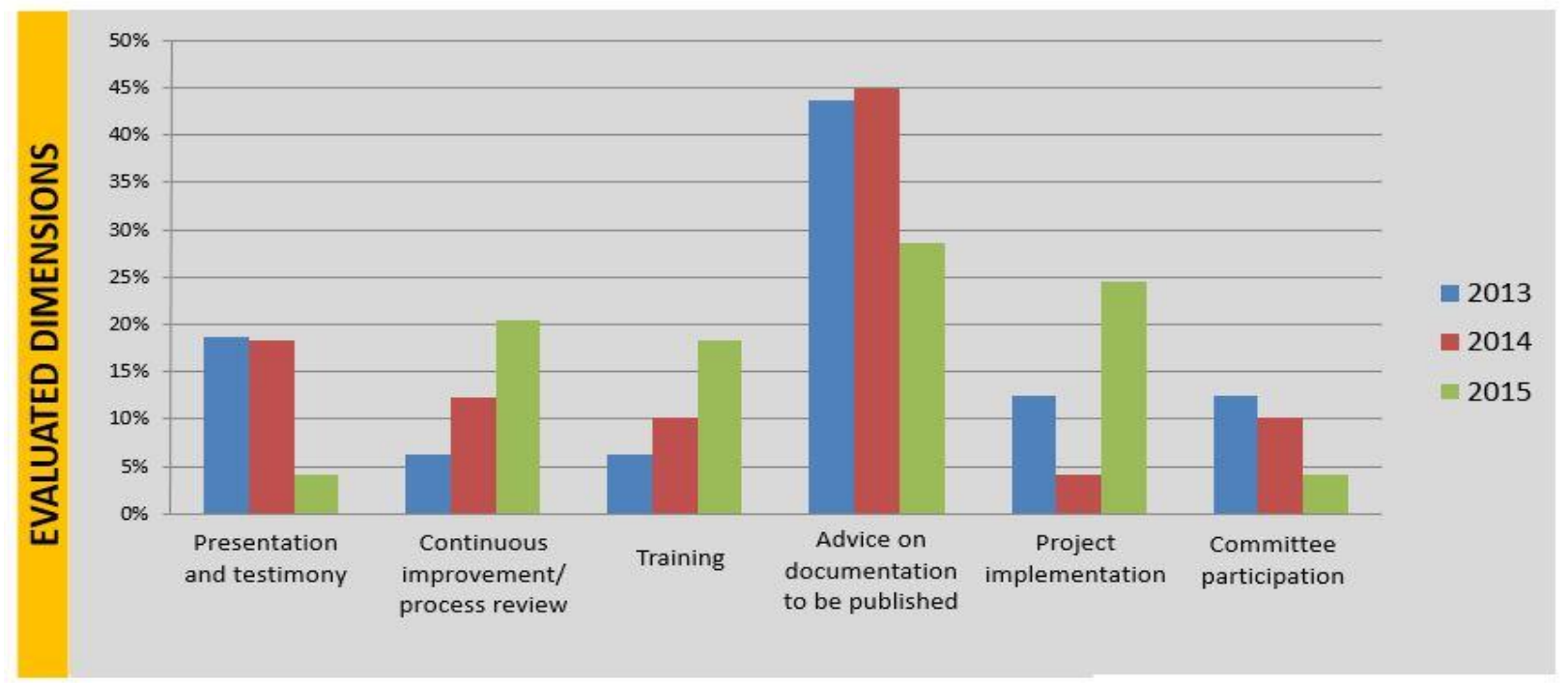

By far, the most common goal of requests was quality and safety of care and services $(64.49 \%)$, followed by accessibility of care and services (18.85\%), and resource optimization $(5.8 \%)$.

Two examples of patient participation in continuous improvement committees are provided in Table 2 below.

\section{Perception of patient advisor contributions}

In all, 38 staff members working in elderly care and outpatient services (28 paramedical staff and 10 health and social services support staff - auxiliaires en santé et services sociaux) were asked to complete a questionnaire regarding the impact of patient testimonies on their practice; all of them responded (Note: All tools used to collect data are available upon request from the principal author.) Among them, $80 \%$ of the paramedical staff and $68 \%$ of the health and social services support staff (auxiliaires en santé et services sociaux) answered that they had altered their practice. They indicated it had given them "a better understanding of the benefit of having patients take an active role in their condition." They also gave greater consideration to the experiential knowledge of patients and their families (100\% of paramedical staff and $82 \%$ of support staff). For example, patient testimonies helped them understand the importance of partnering with patients and of incorporating them into the team and including them in the decisions that affect them: "These testimonies help us focus on the patients and their life experience. I became aware of the need to place more importance on the notion of life plan when identifying treatment objectives"; "I take even more time to explain to users their own importance and their equal role on the team. I try to convince colleagues of the importance of including users during team meetings." Moreover, it helped them communicate with patients better: "I am more careful to communicate with the caregiver family member, to keep them well informed and up-to-date (assuming the patient agrees)." And also: "It helped me improve my listening skills and give more weight to clients' choices and priorities."

Of the 16 out of 24 managers who responded, 94\% found that the mandates for which PAs had been requested did indeed require the involvement of a PA, 77\% found that PA participation had brought added value, and $83 \%$ considered the PAs' preparation useful or even very useful.

The PAs themselves (9 out of 17 responded) considered their participation in various establishment projects to have been useful or very useful in $95 \%$ of cases. They indicated that their level of involvement seemed appropriate in $85 \%$ of cases and that their level of preparation was adequate in $95 \%$ of cases.

The gap between the level of relevance and the level of participation perceived by both managers and PAs can be explained in part by cases where PAs were included in projects late in the process. In such cases, their presence was deemed relevant, but their late arrival prevented them from contributing fully (resulting in a lower level of involvement than might have been desired). 
Table 2. Examples of patient involvement within continuous improvement committees

\begin{tabular}{|c|c|c|c|}
\hline Programs & Team composition & Issue & Deliverable \\
\hline \multirow[t]{3}{*}{ Day hospital } & \multirow{3}{*}{$\begin{array}{l}1 \text { physician } \\
5 \text { patient advisors } \\
2 \text { leaders in interdisciplinary } \\
\text { collaboration }{ }^{1} \text { (LIC) } \\
5 \text { multidisciplinary } \\
\text { practitioners } \\
1 \text { program head }\end{array}$} & $\begin{array}{l}\text { Improve the patient transition process } \\
\text { from the moment of referral to entry } \\
\text { into the day hospital program. }\end{array}$ & $\begin{array}{ll}\text { - } & \text { Draft a pamphlet } \\
\text { - } & \text { Revise the service } \\
& \text { pathway }\end{array}$ \\
\hline & & $\begin{array}{l}\text { Identify ways to evaluate satisfaction for } \\
\text { day hospital patients, to build } \\
\text { recommendations and objectives for } \\
\text { program improvement. }\end{array}$ & $\begin{array}{l}\text { - } \quad \text { Redesign the satisfaction } \\
\text { questionnaire and } \\
\text { compile results }\end{array}$ \\
\hline & & $\begin{array}{l}\text { Draw up a list of suggestions for various } \\
\text { physical activities, to improve participant } \\
\text { motivation. }\end{array}$ & 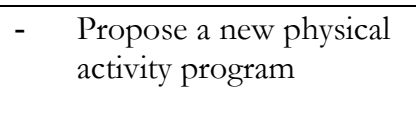 \\
\hline \multirow[t]{3}{*}{$\begin{array}{l}\text { Home } \\
\text { support }\end{array}$} & \multirow[t]{3}{*}{$\begin{array}{l}2 \text { physicians } \\
3 \text { patient advisors } \\
2 \text { leaders in interdisciplinary } \\
\text { collaboration (LIC) } \\
5 \text { multidisciplinary } \\
\text { practitioners } \\
1 \text { program head }\end{array}$} & $\begin{array}{l}\text { Identify relevant information to be } \\
\text { shared among patients, helpers, and } \\
\text { practitioners; create a communication } \\
\text { tool. }\end{array}$ & $\begin{array}{l}2 \text { information kits } \\
\text { prepared for patients } \\
\text { and their families, } \\
\text { communication journal } \\
\text { developed for home- } \\
\text { based services }\end{array}$ \\
\hline & & $\begin{array}{l}\text { Test a communication journal for home- } \\
\text { based services. }\end{array}$ & 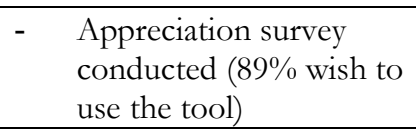 \\
\hline & & $\begin{array}{l}\text { Encourage patients and families to } \\
\text { participate in drafting a care plan, taking } \\
\text { patient's life plan into account. }\end{array}$ & $\begin{array}{l}\text { Development and } \\
\text { dissemination of } \\
\text { pamphlets addressed to } \\
\text { patients and their } \\
\text { families }\end{array}$ \\
\hline
\end{tabular}

1. The leaders in interdisciplinary collaboration (LIC) are managers trained by the University of Montréal to help the organization implement continuous improvement committees

Additionally, the interviews and three group discussions with managers $(\mathrm{M})$, physicians $(\mathrm{P})$, and patient advisors (PA), revealed that involving PAs had brought everyone involved back to the fundamental meaning of the patientpractitioner relationship. Patient participation also had an impact on managers' way of thinking and working. Seeing the benefit of the different viewpoint that patients bring to the analysis of certain situations helped evolve their way of thinking. Managers were also able to better appreciate the value of teamwork and to see the direct impact that patient participation had on patients' therapeutic process and state of health. Finally, patients felt that they were being heard and respected, while being able to contribute news ways of viewing and approaching problems (see Table 3).

\section{Factors helping and hindering implementation}

Of the organizational factors identified during the course of the interviews and group discussions, the ones that contributed the most to patient involvement at the different levels of governance within the CSSS-E were the following (see Table 4): 1) external support provided by the University of Montreal, which helped the HCO set up continuous quality improvement committees that included selected, trained, and coached patient advisors, and by the CFHI, which helped both to remunerate the part-time patient co-lead for the process and to create a community of practice with three other establishments in Québec that had received similar funding; 2) joint leadership by a clinical administrator and a patient; 3) constant engagement and support of senior management, especially the executive director's office, which demonstrated its commitment to the patient partnership approach by making resources available; and 4) the establishment's culture, which fostered interprofessional collaboration and innovation.

Five factors hindering the process were also identified (see Table 5): 1) the difficulty in coordinating patients' and practitioners' schedules to set meetings, especially in the context of working groups; 2) reforms to the Quebec healthcare system, which had come into effect in recent months and which led to major changes in organizational structures, including the merger of the initial centre with several others to form a new, much larger, health and social services establishment covering a 
Table 3. Contributions of patient involvement

\begin{tabular}{|c|c|}
\hline Contributions & Verbatim comments \\
\hline $\begin{array}{l}\text { Returning to the } \\
\text { fundamental meaning of the } \\
\text { patient-practitioner } \\
\text { relationship }\end{array}$ & $\begin{array}{l}\text { "It brings us back to the deeper meaning of what we should be doing in a health } \\
\text { organization. We talk a lot about our patients and we work for the patients, but now we } \\
\text { do things with the patients, and that changes the dynamic." (M) } \\
\text { "It's the relational dimension that we are trying to improve and that we are trying to } \\
\text { teach." (P) } \\
\text { "We arrive with our issues, and they have their own internal issues, to which we bring an } \\
\text { external viewpoint." (PA) }\end{array}$ \\
\hline $\begin{array}{l}\text { Change in how patients are } \\
\text { viewed }\end{array}$ & $\begin{array}{l}\text { "Once we began to listen to patients and to understand what they were contributing, we } \\
\text { became more aware; in fact, their knowledge, their issues, their experience complemented } \\
\text { our knowledge." (M) } \\
\text { "It changed our way of thinking. We thought we were clinical experts, but the } \\
\text { partnership brought us back to the learner's role, which opened us up, and we became } \\
\text { more aware!" (P) }\end{array}$ \\
\hline Enhanced teamwork & $\begin{array}{l}\text { "Feeling the dynamics of quality teamwork, where each team-member is valued and every } \\
\text { strength is acknowledged, in the interest of providing the best support for the patient to } \\
\text { reach a better state of health." (M) }\end{array}$ \\
\hline $\begin{array}{l}\text { Impact on patients' state of } \\
\text { health }\end{array}$ & $\begin{array}{l}\text { "Their involvement in committees had an effect on their adherence to the care or } \\
\text { recovery process." (P) } \\
\text { "The patients felt that they were on equal footing with others and that everyone was } \\
\text { listening to them; this was a kind of stress that they were able to manage, which helped } \\
\text { them gain self-confidence and later go out and seek employment." (M) }\end{array}$ \\
\hline (Self) respect for patients & $\begin{array}{l}\text { "I received services here, and now it's my turn to give, so that other patients can benefit." } \\
\text { (PA) } \\
\text { "It's like feeling that what I contribute is just as important as what others do, there's less } \\
\text { of a hierarchy, and I can discuss my point of view, which is always taken into account by } \\
\text { the team." (PA) }\end{array}$ \\
\hline
\end{tabular}

larger territory; 3) the difficulty of getting physicians involved, since they are independent of the centre's structures and have little financial incentive to participate in non-clinical activities; 4) the status of PAs, who are currently volunteers as there is no official budget to remunerate them for time spent at the centre; 5) PAs' state of health, which sometimes obliges them to reduce their participation in working groups.

\section{Limitations of the framework and of the evaluation}

One of the main limitations of the framework is that the part-time patient lead was hired with funding from CFHI. Currently, CSSS-E does not have a dedicated budget to remunerate this position so that it can continue to support the patient involvement framework in collaboration with a manager. Another limitation is that the PAs are not remunerated for their involvement; their only recognition they receive for their invaluable work is the feedback obtained on their assignments. Since few managers and practitioners find the time to provide feedback, a procedural step for evaluation and follow-up with managers and practitioners was added to the end of each assignment.

Regarding the evaluation, it would have been useful to conduct more interviews and discussion groups at the end of the project, but this was not possible due to the previously mentioned major reform of the Québec healthcare system. ${ }^{3}$ Indeed, the CSSS-E was merged with 12 other establishments to form the Centre intégré universitaire de santé et de services sociaux de la Mauricieet-du-Centre-du-Québec (CIUSSS-MCQ). Over the subsequent nine months, almost all of the managers were recruited or replaced. Another limitation is the fact that, due to limited resources, the results were not broken down by type of patient participation (nature of the activity, work group composition, number of PAs involved, duration of the activity, etc.). It would be useful for future research to investigate whether results for patient involvement at the tactical and strategic levels are different from those at the clinical level. Moreover, we were hampered by a low questionnaire response rate, which may be explained on the PA side by their lack of familiarity with electronic questionnaires and with IT difficulties. As for professionals, due to restructuring, many no longer occupied the same position as when they had worked with a PA. Finally, in some cases the managers were not those 


\section{Table 4. Facilitating factors}

\begin{tabular}{|c|c|}
\hline Factors & Verbatim comments \\
\hline External support & $\begin{array}{l}\text { "The support from the University of Montreal's DCPP [Direction Collaboration Partenariat } \\
\text { Patient-Collaboration and Patient Partnership Unit], which at the outset, provided } \\
\text { coaching on how to deploy continuous improvement committees involving patients." (M) } \\
\text { "Having a grant from the Canadian Foundation [CFHI] is a very positive element for us, } \\
\text { since it gives us more internal legitimacy as well as the opportunity to share experiences } \\
\text { with other patients from other establishments." (PA) }\end{array}$ \\
\hline $\begin{array}{l}\text { Joint clinical- } \\
\text { administrative/patient team }\end{array}$ & $\begin{array}{l}\text { "Hiring a patient to lead the process jointly with a clinical manager was the key to } \\
\text { success, as it ensured that patients' point of view, their constraints, expectations, and } \\
\text { contributions were always kept in mind." (M) } \\
\text { "The contribution of a patient involved two days a week made all the difference, we were } \\
\text { able to work with her very easily, and she supported us in our work." (PA) }\end{array}$ \\
\hline $\begin{array}{l}\text { Commitment of executive } \\
\text { directors }\end{array}$ & $\begin{array}{l}\text { "The executive director's commitment, from the start of the project, to including it the } \\
\text { establishment's strategic planning, with the objective of having } 50 \% \text { of clinical } \\
\text { departments set up partnership of care, and to appoint a senior advisor, } 75 \% \text { of whose } \\
\text { time was dedicated to the project." (M) } \\
\text { "The executive director's office, which gave us its support in ironing out difficulties, as } \\
\text { this is a new way of functioning." (PA) }\end{array}$ \\
\hline CSSS-E's culture & $\begin{array}{l}\text { "The culture of interprofessional collaboration makes partnership of care a lot easier." (P) } \\
\text { "People have made an effort to adapt professional language and to explain jargon to } \\
\text { facilitate communication." (M) } \\
\text { "I felt that I was a full-fledged member of the team, which reflects the team's openness to } \\
\text { talking with that person. PP is something that makes people's lives easier." (PA) }\end{array}$ \\
\hline
\end{tabular}

who had completed the assignment with the PA, which meant they were not necessarily the best person to answer the questionnaire. This may also have affected the results.

Finally, the lack of indicators to measure the impact of patient participation at the clinical, organizational, and tactical levels precluded tracking changes brought about in the establishment's culture, its governance, and the quality and safety of its care and services over time. ${ }^{30}$

\section{Challenges following the merger}

During the 18-month period of funding from the Canadian Foundation for Healthcare Improvement (CFHI), ${ }^{22}$ the Québec healthcare system underwent a massive reform during which the CSSS-E was merged to form the Centre intégré universitaire de santé et de services sociaux de la Mauricie-et-du-Centre-du-Québec (CIUSSS-MCQ). ${ }^{10}$ This new centre employs a workforce of 14,367 full-time equivalents and coordinates care and services (hospital care, ambulatory care, primary care, longterm care, centre for child and youth protection, rehabilitation centres, public health) for a population of 510,163 over a territory of 42,331 square kilometres including 127 facilities.

The merger, which took effect on April 1 ${ }^{\text {st }}, 2015$, led to changes in the organizational structure and the recruitment of new persons. This period of change presented both opportunities - in that the notion of patient partnership is now established in the establishment's organizational chart, and CSSS-E has become a model establishment for exporting the process - and challenges, as the services that had used PAs have since been restructured and the managers involved have almost all moved. The coordinating team has suffered cuts, as the patient counselor is no longer employed and the social worker's hours dedicated to promoting and implementing partnership throughout the establishment have been reduced. This new team's challenge is therefore to pursue its mission to promote and raise awareness of the partnership approach with new managers and develop strategies based on the lessons learned by the CSSS-E. These strategies draw on a number of principles, shared below, which could help other establishments interested in developing a similar process.

\section{Conclusion and recommendations}

This article describes an initiative that provides some guidance on how to plan, implement, promote, evaluate, and improve patient partnership in an HCO. Following the experience acquired and the challenges faced by the establishment during the course of the merger, we offer these recommendations, which are drawn from the lessons learned during the project funded by CFHI, to help any healthcare establishments/networks, local or international, wishing to structure patient involvement at all governance levels: 
- $\quad$ Surveying existing processes to obtain a detailed overview of initiatives involving patients. This survey also helps identify leaders who are already promoting patient partnership, so they can be involved throughout the process.

- Getting buy-in from the board of directors, the executive director, and senior management, so they can support the project and take it into account in all their actions.

- Establishing working groups consisting of managers, health professionals, and patients, to develop a shared vision of partnership of care and services for the entire organization. Recruiting these representatives from various parts of the establishment ensures a wide range of viewpoints are collected.

- Creating an interdisciplinary committee (managers, practitioners, PAs) with a mandate to work on deployment strategies for a partnership of care and services approach across the whole establishment ${ }^{14,15,31}$ :

- Drafting a practical guide for managers based on the theoretical model of patient involvement;

- Draft an organizational policy related to patient involvement that defines the roles of everyone involved;

- Develop a broad communications plan to spread awareness of the importance of involving patients at all levels of governance of the establishment.

- Entrusting the patient involvement framework to a joint patient-manager leadership responsible for: 1) promoting the process at all levels of governance; 2) training managers, health professionals, and patients on partnership of care; 3) selecting, training, and coaching patients to develop a pool of patients meeting the needs of mandates as required; 4) supporting initiatives already underway and foster new ones; 5) creating tools to support patient involvement (such as patient recruitment sheets and functional role descriptions); 6) facilitating PA meetings so they can share their experiences; and 7) training PAs so they can themselves become trainers;

- Allocating resources to support patient involvement where possible (e.g., parking stickers, identification cards, reimbursement for mileage, meals, etc.);

- Committing to a process for continuous improvement of patient involvement practices, taking into account the local context and respecting the basic principles of patient involvement.

\section{Table 5. Limiting factors}

\begin{tabular}{|l|l|}
\hline Factors & Verbatim comments \\
\hline Scheduling & $\begin{array}{l}\text { "We always have the same type of patient, that is, patients who are retired or } \\
\text { who don't work, or persons who say 'I do this' but have an non-regular } \\
\text { schedule. So patients who work Monday to Friday from 8am to 4pm can } \\
\text { never be patient advisors. We also need to adapt our services so that these } \\
\text { patients can participate. We want to benefit from them, so they should also } \\
\text { benefit." (M) }\end{array}$ \\
\hline "Having a larger territory will make it harder to remain close to patients and \\
get to know them personally in order to recruit them." (M)
\end{tabular}




\section{References}

1. Carman KL, Dardess, P, Maurer M, Sofaer S, Adams K, Bechtel C. Patient and family engagement: a framework for understanding the elements and developing interventions and policies. Health Affairs. 2013; 32(2): 223-231.

2. Jouet E, LasVergnas O, Flora L. Priznavanjeizkustvenegaznanjabolnikovinbolnicpregledstanja [Patients' experientialknowledgerecognition-astateoftheart]. SocialnoDelo. 2012; 51(1-3):87-99.

3. Karazivan P, Dumez V, Flora L, Pomey MP, Del Grande C, Ghadiri DP. The Patient-as-Partner Approach in Health Care: A Conceptual Framework for a Necessary Transition. Acad Med. 2015; 90(4): 437-441.

4. Lehrman WG, Silvera GA, Wolf JA. The Patient Experience Movement Moment. Patient Experience Journal. 2014; 1(2): 9-11.

5. Pomey MP, Flora L, Karazivan P, Dumez V, Lebel P, Vanier MC, et al. Le "Montreal model": enjeux du partenariat relationnel entre patients et professionnels de la santé. Santé Publique. 2015;HS (S1):41-50.

6. Richards T, Montori VM, Godlee F, Lapsley, P, Paul D. Let the patient revolution begin. BMJ. (2013); 346. doi: http://dx.doi.org/10.1136/bmj.f2614.

7. Batalden M, Batalden P, Margolis P, Seid M, Armstrong G, Opipari-Arrigan L, et al. Coproduction of healthcare service. BMJ Qual Saf. 2015. doi:10.1136/bmjqs-2015-004315.

8. Golden BR, Hannam R, Fraser H, Leung M, Downey

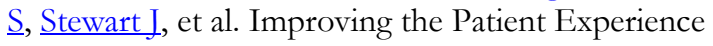
through Design. Healthc Q. 2011;14(3): 32-41.

9. Simpson EL, House AO. Involving users in the delivery and evaluation of mental health services: systematic review. BMJ. 2002; 325(7375): 1265. doi:10.1136/bmj.325.7375.1265.

10. Pomey MP, Hihat H, May K, Lebel P, Néron A, Dumez V. Patient partnership in quality improvement of healthcare services: Patients' inputs and challenges faced. Patient Experience Journal. 2015; 2(1):29-42.

11. Berkesse A, Marquis JG. Le partenariat avec les patients dans les démarches d'amélioration continue des soins et services de santé. Construire ensemble les milieux de soins de demain. Communication présentée à Regards croisés France/Québec : co-construction en partenariat avec les patients et les citoyens dans le système de santé, la formation et la recherche, Montréal, Canada ; november 2015.

12. Boivin A, Currie K, Fervers B, Gracia J, James M, Marshall $\mathrm{C}$ et al. Patient and public involvement in clinical guidelines : international experiences and future perspectives. Qual Saf Health Care. 2010; 19(5): e22. doi:10.1136/qshc.2009.034835.

13. Jones SP, Auton MF, Burton CR, Watkins CL. Engaging service users in the development of stroke services: an action research study. J Clin Nurs. 2008;17(10):1270-9.

14. Groene O, Lombarts MJMH, Klazinga N, Alonso J, Thompson A, Suñol R. Is patient-centredness in European hospitals related to existing quality improvement strategies? Analysis of a cross-sectional survey (MARQuIS study). Qual Saf Health Care. 2009; 18(Suppl 1): i44-i50. doi:10.1136/qshc.2008.029397.

15. Groene O, Sunol R, Klazinga NS, Wang A, Dersarkissian M, Thompson CA, Arah O. A. Involvement of patients or their representatives in quality management functions in EU hospitals: implementation and impact on patient-centred care strategies. Int J Qual Health Care. 2014; 26 Suppl 1:8191. doi:10.1093/intqhe/mzu022.

16. Gagliardi AR, Lemieux-Charles L, Brown AD, Sullivan T, Goel, V. Barriers to patient involvement in health service planning and evaluation: an exploratory study. Patient Educ Couns. 2008; 70(2), 234-241. doi:10.1016/j.pec.2007.09.009.

17. Oliver S, Clarke-Jones L, Rees R, Milne R, Buchanan $\mathrm{P}$, Gabbay J et al. Involving consumers in research and development agenda setting for the NHS: developing an evidence-based approach. Health Technol Assess. 2004; 8(15), 1-148, iii-iv.

18. Mitton C, Smith N, Peacock S, Evoy B, Abelson J. Public participation in health care priority setting:A scoping review. Health Policy.2009; 91 (3):219-228. doi:10.1016/j.healthpol.2009.01.005.

19. Bombard Y, Baker RG, Orlando E, Fancott C, Bhatia $\mathrm{P}$, Onate $\mathrm{K}$, et al. Engaging patients to improve quality care: A systematic review. Submitted to BMJ Qual Saf. bmjqs-2014-003403. R1 december (2014).

20. Armstrong N, Herbert G, Aveling EL, Dixon-Woods M, Martin, G. Optimizing patient involvement in quality improvement. Health Expectations. 2013;16(3), e36-e47. doi:10.1111/hex.12039.

21. Gravel K, Légaré F, Graham, ID. Barriers and facilitators to implementing shared decision-making in clinical practice: a systematic review of health professionals' perceptions. Implement Sci. 2006; 1 :1616. doi:10.1186/1748-5908-1-16.

22. What we do. Partnering with patients and families collaborative. Canadian Foundation for Healthcare Improvement (CFHI). http://www.cfhifcass.ca/WhatWeDo/partnering-with-patients-andfamilies-collaborative. Updated January 2016. Accessed January 15th 2016.

23. Gouvernement du Québec. PL10, Loi modifiant l'organisation et la gouvernance du réseau de la santé et des services sociaux notamment par l'abolition des agences régionales. 1ere session, 41è législature, Québec, 2015 (sanctionnée le 9 février 2015).

24. Pomey MP, Ghadiri, DP, Karazivan P, Fernandez N, Clavel N. Patients as Partners: A Qualitative Study of Patients' Engagement in Their Health Care. PLoS One. 2015; 10(4): e0122499. 
25. Centre de pédagogie appliquée aux sciences de la santé (CPASS) de l'Université de Montréal. Guide d'implantation du partenariat de soins et de services, vers une collaboration optimale entre intervenants et avec le patient \{Centre of applied pedagogy (education) in health science (CPASS), University of Montreal. Guide of implementation of partnership of care and services, towards an optimum collaboration between professionals and patients\}. Montréal : Université de Montréal, Direction collaboration et partenariat patient/CPASS ; 2013. Available at:

http://www.ruis.umontreal.ca/documents/Guide_im plantation.pdf (Accessed on August 29, 2015).

26. McNally D, Sharples S, Craig G, Goraya A. Patient leadership: Taking patient experience to the next level? Patient Experience Journal. 2015; 2(2):7-15.

27. Kendell C, Urquhart R, Petrella J, Macdonald S, McCallum M. Evaluation of an advisory committee as a model for patient engagement. Patient Experience Journal. $2014 ; 1(2): 62-70$.

28. Pomey MP, Vigneault K, Arsenault J, Higgins J, Lahaie V, Fortin O et al. Le patient-ressource chez les victimes d'amputation traumatique. La Revue $d u$ Praticien. $2015 ; 65: 1215$.

29. Centre de pédagogie appliquée aux sciences de la santé (CPASS) de l'Université de Montréal. Pratique collaborative: engagement et leadership \{Centre of applied pedagogy (education) in health science (CPASS), The University of Montreal. Collaborative practice : engagement and leadership\}. Montréal : Université de Montréal, Direction collaboration et partenariat patient/CPASS ; 2013. Available at : http://www.ruis.umontreal. $\mathrm{ca} /$ documents/Rapport_engagement_et_leadership.p df (Accessed August 29, 2015).

30. Raleigh VS, Frosini F, Sizmur S, Graham C. Do some trusts deliver a consistently better experience for patients? An analysis of patient experience across acute care surveys in English NHS trusts. BMJ Qual Saf. 2012; 21(5): 381-390.

31. Aboumatar HJ, Chang BH, Al Danaf J, Shaear M, Namuyinga R, Elumalai S, et al. Promising Practices for Achieving Patient-centered Hospital Care: A National Study of High-performing US Hospitals. Med Care. 2015; 53(9): 758-767.

32. Vigneault K, Hoggins J, Pomey MP, Arsenault J, Lahaie V, Mercier AM, et al. Bringing patients advisors to the bedside: a promising avenue for improving partnership between patients and their health care team. Patient Experience Journal. 2015; 2(2): 16-22.

33. World Health Organization (WHO). Therapeutic patient education. Continuing education programs for health care providers in the field of prevention of chronic diseases. Copenhagen: World Health Organization Regional Office for Europe; 1998.
34. Tourette-Turgis C. Savoirs de patients, savoirs de soignants: La place du sujet supposé savoir en knowledge of caregivers: The place of the place supposed subject of knowledge in therapeutic education. Pratiques de formation: Analyses. 2010 :58/59 135-51 


\section{Appendix 1. The request form}

\begin{tabular}{|c|c|c|c|c|}
\hline \multicolumn{5}{|c|}{$\begin{array}{l}\text { SECTION 1 } \\
\text { (to be completed by the manager or the contact person/ originator of the request) }\end{array}$} \\
\hline \multicolumn{2}{|l|}{ Manager: } & \multicolumn{3}{|c|}{ Department: Choisissez un élément. } \\
\hline \multicolumn{2}{|l|}{ Date: $\mathrm{xx}$} & \multicolumn{3}{|c|}{$\begin{array}{l}\text { The purpose of this request is } \\
\text { (check the answer(s) that apply) }\end{array}$} \\
\hline \multicolumn{2}{|c|}{$\begin{array}{l}\text { What objective does this request serve? Choisissez } \\
\text { un élément. }\end{array}$} & \multirow{2}{*}{\multicolumn{3}{|c|}{$\begin{array}{l}\square \text { Accessibility of care and services (accessibility, equity of access) } \\
\square \text { Quality of care and services (efficiency, safety, responsiveness, } \\
\text { continuity) } \\
\square \text { Resource optimization (efficiency, sustainability) } \\
\square \text { Client experience } \\
\square \text { Practitioner well-being }\end{array}$}} \\
\hline \multicolumn{2}{|l|}{ Explain (brief description): } & & & \\
\hline \multirow{3}{*}{\multicolumn{2}{|c|}{$\begin{array}{l}\text { Contact person for the patient advisor (responsible } \\
\text { for } 1^{\text {st }} \text { contact) } \\
\text { Name: }\end{array}$}} & \multicolumn{3}{|l|}{ Position: } \\
\hline & & \multicolumn{3}{|l|}{$@$} \\
\hline & & $\overline{\mathbf{0}}$ & & Extension: \\
\hline \multicolumn{5}{|c|}{ Number of patient advisor(s) required: } \\
\hline \multirow{3}{*}{$\begin{array}{l}\text { Patient advisor profile } \\
\text { Your assignment requires... }\end{array}$} & \multicolumn{2}{|c|}{$\square$ specific location/site } & \multicolumn{2}{|l|}{ Specify: } \\
\hline & \multicolumn{2}{|c|}{$\square$ experience of care and services } & \multicolumn{2}{|l|}{ Specify: } \\
\hline & \multicolumn{2}{|c|}{$\square$ other competencies } & \multicolumn{2}{|l|}{ Specify: } \\
\hline \multicolumn{5}{|c|}{ Is a preliminary meeting required? $\quad \square$ YES $\square$ NO } \\
\hline \multicolumn{5}{|l|}{ OTHER COMMENTS } \\
\hline
\end{tabular}




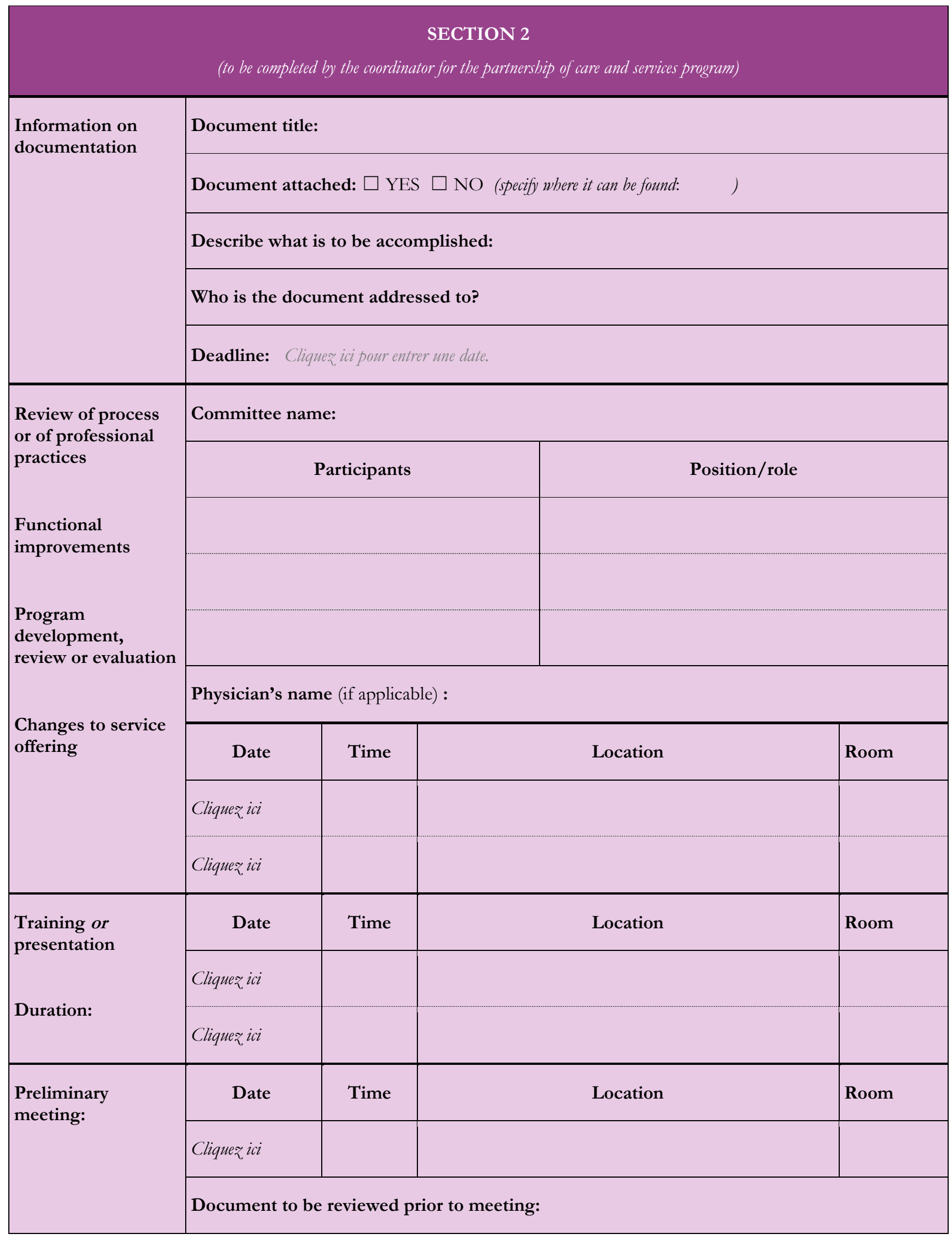


Is the team authorized to work with a patient advisor?

\section{YES $\square \mathrm{NO}$}

\section{ADDITIONAL INFORMATION}

\begin{tabular}{|c|c|c|c|}
\hline \multicolumn{4}{|c|}{$\begin{array}{l}\text { SECTION } 3 \\
\text { be completed by the coordinator for the partnership of care and services program) }\end{array}$} \\
\hline Request level & $\square$ care and services $\quad \square$ tactical & \multicolumn{2}{|l|}{$\square$ strategic } \\
\hline Patient advisor available & \multicolumn{3}{|l|}{$\square$ YES $\square$ NO (need to recruit) } \\
\hline Assign a patient-coach & \multicolumn{3}{|l|}{$\square$ YES $\square$ NO } \\
\hline \multirow[t]{3}{*}{ Patient name(s) } & Type of patient & & Assignment date \\
\hline & Choisissez un élément. & & \\
\hline & Choisissez un élément. & & \\
\hline
\end{tabular}

\begin{tabular}{|c|c|c|c|}
\hline \multicolumn{4}{|c|}{ SECTION 4} \\
\hline \multicolumn{4}{|l|}{ End of assignment } \\
\hline \multirow[t]{3}{*}{ Patient name(s) } & Level of satisfaction & Comments & Follow-up date \\
\hline & $\square 1 \square 2 \square 3 \square 4 \square 5$ & & \\
\hline & $\square 1 \square 2 \square 3 \square 4 \square 5$ & & \\
\hline Satisfaction / contact person & $\square 1 \square 2 \square 3 \square 4 \square 5$ & & \\
\hline
\end{tabular}

Thank you for co-constructing better care with your patients! 